\title{
Life Style Factors Associated with Premenstrual Syndrome among El-Minia University Students, Egypt
}

\author{
Amany Edward Seedhom, Eman Sameh Mohammed, and Eman Mohammed Mahfouz \\ Department of Public Health and Preventive Medicine, Faculty of Medicine, El-Minia University, University Street, \\ El-Minia 1666, Egypt \\ Correspondence should be addressed to Amany Edward Seedhom; amany_medhat@yahoo.com
}

Received 11 March 2013; Accepted 18 April 2013

Academic Editors: N. Kontodimopoulos, T. Morken, and G. Rahav

Copyright (c) 2013 Amany Edward Seedhom et al. This is an open access article distributed under the Creative Commons Attribution License, which permits unrestricted use, distribution, and reproduction in any medium, provided the original work is properly cited.

\begin{abstract}
Aim. To determine the score and frequency of premenstrual syndrome (PMS) among female college students and to detect the possible risk factors of PMS. A trial of life style modification regarding prevention and control of PMS symptoms was carried out using counseling. Materials and Methods. A cross-sectional study was conducted on 253 El-Minia University unmarried female students. A self-administered questionnaire inquiring about symptoms of PMS in the previous three months and risk factors possibly related to it was used. PMS score was calculated. Multiple regression analysis was performed to determine which of several biopsychosocial and dietary factors influenced PMS. Life style modification counseling was done to prevent and control PMS. Results. The study revealed that $80.2 \%$ of the participants experienced various degrees of PMS symptoms which were significantly associated with a family history of PMS, physical inactivity, habitual excess consumption of coffee, BMI, frequent consumption of fast food, and smoking, but these factors explained only $52 \%$ of the variability in the logistic regression model. Conclusion. We recommend the introduction of a reproductive health component into school and college health education programs and encourage female adolescents and young adults to adopt a healthy behavior.
\end{abstract}

\section{Introduction}

Premenstrual tension syndrome (PMS) is one of the most common disorders in women at reproductive age that could significantly interfere with activities of daily life. PMS is a set of physical and psychological symptoms that arises about a week to ten days before menstruation. Premenstrual symptoms usually relieve or ease once menstruation starts. But they might continue for the first few days of the period. If the problem really is PMS, though, it will go away and then it will come back with the next cycle [1].

Menstruation is a normal phenomenon which is an important indicator of women's health [2]. However, data on experiences of menstruation and its impact on the health status, quality of life, and social integration among women in developing countries are scant [3].

The American College of Obstetrics and Gynecology (ACOG) published the diagnostic criteria for PMS. It is considered if at least one of the 6 affective and one of the 4 somatic symptoms are reported 5 days prior to onset of menses in prior 3 cycles and cease within 4 days of onset of menses. There are numerous emotional and behavioral symptoms such as depression, angry outbursts, irritability, crying spells, anxiety, confusion, social withdrawal, poor concentration, as well as sleep disturbance, thirst, and appetite changes. There are also physical symptoms including breast tenderness, bloating, and weight gain, in addition to headache, swelling of hands or feet, and aches or pains. It is estimated that up to $85 \%$ of women who menstruate experience at least one premenstrual symptom, occurring within 2 weeks before menses and easing after menses begins [4].

Various biosocial and psychological causes have been proposed as the cause of the syndrome, including abnormal serotonin function, presence of progesterone, altered endorphin modulation of gonadotrophins secretion, exercise habits, smoking, use of alcohol, altered transcapillary fluid balance, and a diet rich in beef or caffeine containing beverages [5]. 
Adiposity may also be related to PMS through a variety of hormonal, neural, and behavioral mechanisms, and several studies have found women with PMS or menstrual symptoms more likely to be overweight and obese than women without PMS [6].

PMS is not real life threatening but it can seriously alter the quality of life of many women and affect their productivity and mental health [7]. The number of women seeking treatment for premenstrual symptoms is on the rise [8].

Therefore, in this study, the frequency and severity of PMS among female adolescent and young adults in ElMinia University, Egypt, is studied. They are already under a lot of academics-related stress, and therefore there is a need to explore the PMS problem and the added stress that could impact them which may jeopardize their quality of life and negatively affect activities of daily living. The potential association between the manifestations of PMS as dependent variables and diet, BMI, and demographic and behavioral factors as independent variables was determined to use the information in tailoring counseling session regarding lifestyle modification to improve PMS.

A healthy lifestyle is the first step to managing PMS. For many women, lifestyle approaches are often enough to control symptoms. The following is an example of a lifestyle modification advice.

(i) Drink plenty of fluids (water or juice, not soft drinks, alcohol or other beverages with caffeine) to help reduce bloating, fluid retention, and other symptoms.

(ii) Eat frequent small meals, leave no more than 3 hours between snacks, and avoid overeating.

(iii) Eat balanced diet with extra whole grains, vegetables, and fruit and less or no salt and sugar.

(iv) A health care provider may recommend nutritional supplements as vitamin B6, calcium, and magnesium.

(v) Get regular aerobic exercise throughout the month to help reduce the severity of PMS symptoms [9].

\section{Materials and Methods}

This cross-sectional study was conducted on El-Minia University female students during the first term of the academic year 2012-2013 with the following objectives:

(1) assess the frequency of PMS among college students;

(2) detect the PMS severity score among participants;

(3) determine the association between PMS frequency and possible risk factors of the disease.

\section{Criteria of Inclusion in This Study}

Unmarried El-Minia University female students aged between 18 and 25 years.

Sample. The sample was derived from four faculties chosen randomly from a listing frame representing all faculties of
El-Minia University. The total sample was distributed in the four faculties proportionate to number of students in each faculty. The sample size was calculated using the equation considering the percentage of PMS, confidence level, and margin of error.

Formula. $n=t^{2} \times p(1-p) / m^{2}$.

Description

$n=$ required sample size.

$t=$ confidence level at 95\% (standard value of 1.96 ).

$p=$ estimated prevalence of PMS in the study area (80\%).

$m=$ margin of error at $5 \%$ (standard value of 0.05 ).

$n=(1.96)^{2} \times 0.8(1-0.8) /(0.05)^{2}$.

$n=\sim 246$.

The female students in the chosen faculties were invited to participate in this study through a declaration posted on the entrance of each faculty and those who agreed to participate were included in the study. They were told that their responses would remain confidential.

Data were collected by a self-administered structured questionnaire that included sociodemographic data, PMS symptoms in the last three cycles, family history, and its possible risk factors (dietary habits and physical exercise). Each participant was given 20 minutes to complete the questionnaire. Scores were assigned based on whether the symptom was described as mild (score $=1$; noticeable but not troublesome), moderate (score $=2$; interfere with daily activities), severe (score $=3$; intolerable), and not at all (given score 0 ). Each female student was assigned a PMS symptom score from 0 (no symptoms) to 42 (maximum of 14 severe symptoms) [10].

The following measurements were taken: weight, height, and waist and hip circumferences. This was followed by a healthy life style lecture. The investigators discussed the definition of PMS, its risk factors, and how to prevent and control its symptoms through life style modification and answered students' queries in this regard.

Data Analysis. Data from the questionnaires was revised, coded, and entered on a personal computer. The Statistical Package for Social Science (SPSS) for Windows (version 11.0) for statistical analysis was used.

Ethical Consideration. Approval was taken from the ethical committee of Faculty of Medicine El-Minia University. Before starting the study, a verbal consent was obtained and then the female students were briefed about the rational of the study.

\section{Results}

The age of the students ranged from 17 to 23 years with a mean age $( \pm \mathrm{SD})$ of $18.8 \pm 0.9$ years, weight ranged between 39 and $100 \mathrm{~kg}$ (mean \pm SD: $61.5 \pm 10.7$ ), height ranged between 139 and $176 \mathrm{~cm}$ (mean \pm SD: $159.9 \pm 5.7)$, BMI ranged between 16.2 and $36.7 \mathrm{~kg} / \mathrm{m}^{2}$ (mean \pm SD: $24.1 \pm 4$ ), waist circumference ranged between 60 and $97 \mathrm{~cm}$ (mean \pm SD: 76.8 \pm 8.1 ), and hip circumference ranged between 75 and $123 \mathrm{~cm}$ (mean $\pm \mathrm{SD}$ : 
TABLE 1: Distribution of El-Minia University students according to PMS score.

\begin{tabular}{lcc}
\hline PMS score & $N$ & $\%$ \\
\hline $0-9$ no or mild & 55 & 21.7 \\
$10-29$ moderate & 164 & 64.8 \\
$\geq 30$ severe & 34 & 13.4 \\
\hline Total & 253 & 100 \\
\hline
\end{tabular}

TABLE 2: Ranking of premenstrual symptoms according to severity $(N=253)$.

\begin{tabular}{|c|c|c|c|c|c|c|}
\hline \multirow{2}{*}{ Symptom } & \multicolumn{2}{|c|}{ Mild } & \multicolumn{2}{|c|}{ Moderate } & \multicolumn{2}{|c|}{ Severe } \\
\hline & $N$ & $\%$ & $N$ & $\%$ & $N$ & $\%$ \\
\hline Fatigue & 63 & 24.9 & 72 & 28.5 & 88 & 34.8 \\
\hline Mood swings & 77 & 30.4 & 72 & 28.5 & 73 & 28.9 \\
\hline Anxiety & 68 & 26.9 & 51 & 20.2 & 61 & 24.1 \\
\hline Irritability & 72 & 28.5 & 64 & 25.3 & 55 & 21.7 \\
\hline Heavy aching legs & 42 & 16.6 & 44 & 17.4 & 48 & 19 \\
\hline Insomnia & 62 & 24.5 & 51 & 20.2 & 46 & 18.2 \\
\hline Nervous tension & 98 & 38.7 & 60 & 23.7 & 45 & 17.8 \\
\hline Depression & 68 & 26.9 & 44 & 17.4 & 45 & 17.8 \\
\hline Confusion & 75 & 29.6 & 39 & 15.4 & 38 & 15 \\
\hline Crying & 49 & 19.4 & 47 & 18.6 & 33 & 13 \\
\hline Excessive thirst & 66 & 26.1 & 42 & 16.6 & 33 & 13 \\
\hline Headache & 82 & 32.4 & 42 & 16.6 & 32 & 12.6 \\
\hline Craving of sweets & 49 & 19.4 & 45 & 17.8 & 28 & 11.1 \\
\hline Forgetfulness & 60 & 23.7 & 40 & 15.8 & 26 & 10.3 \\
\hline Abdominal bloating & 74 & 29.2 & 44 & 17.9 & 25 & 9.9 \\
\hline Disorientation & 56 & 22.1 & 17 & 6.7 & 20 & 7.9 \\
\hline Heart pounding & 50 & 19.8 & 33 & 13 & 18 & 7.1 \\
\hline Increase in appetite & 50 & 19.8 & 48 & 19 & 17 & 6.7 \\
\hline Dizziness or fainting & 63 & 24.9 & 26 & 10.3 & 15 & 5.9 \\
\hline Bad breath & 67 & 26.5 & 23 & 9.1 & 14 & 5.5 \\
\hline Increase in physical activity & 51 & 20.2 & 37 & 14.6 & 13 & 5.1 \\
\hline Breast tenderness & 43 & 17 & 29 & 11.5 & 12 & 4.7 \\
\hline Weight gain & 34 & 13.4 & 32 & 12.6 & 10 & 4 \\
\hline
\end{tabular}

$99.5 \pm 7.7)$. There were $92(36.4 \%)$ from rural areas and 161 $(63.6 \%)$ were urban.

The premenstrual symptom scores ranged from 0 to 42 . Of the 253 students, 203 (80.2\%) had PMS. Fifty-five (21.7\%) had a premenstrual symptom score ranged from 0 to 9 and $34(13.4 \%)$ had a premenstrual symptom score greater than 30 which was considered moderate to severe PMS as shown in Table 1.

It was found that the severe PMS symptoms were as follow: Severe fatigue (34.8\%), severe mood swings $(28.9 \%)$, severe anxiety $(24.1 \%)$, severe irritability $(21.7 \%)$ and $(19 \%)$ heavy aching legs (Table 2).

In Table 3, it was found that there was a significant relation between BMI and the occurrence of PMS. As all the underweight female students had PMS and 93.4\% and $90.9 \%$ of overweight and obese students, respectively, had PMS compared to $6.6 \%$ and $9.1 \%$ who had no PMS, this difference was statistically significant $(P=0.003)$. PMS was higher among students who had central obesity versus those who had not $(92.9 \%$ versus $7.1 \%)$, but this difference was statistically not significant $(P=0.2)$.

Family history of PMS exerted a significant influence on the occurrence of premenstrual symptoms. PMS was detected in about $93 \%$ of female students with a positive family history of PMS compared to (76\%) without a family history of PMS $(P=0.003)$. A significant relationship was observed between exposure to passive smoking and PMS, as $83.5 \%$ of those who exposed to passive smoking had PMS compared to $66 \%$ of those who did not expose to passive smoking $(P=0.006)$. A larger proportion of students who were sedentary (91\%) had PMS compared to those women (49.2\%) who were physically active $(P<0.0001)$ (Table 4$)$.

Excess intake of sweet-tasting food items such as chocolates, cakes, and deserts had a significant influence on the occurrence of PMS, as students who ate these food items frequently had PMS (88.5\%) more than those $(70.2 \%)$ who consumed them less often $(P<0.0001)$. A similar observation was made for students who consumed excess fast food as $71.4 \%$ of them had PMS. Decreased intake of fruits and vegetables was significantly related to the occurrence of PMS. About $86 \%$ of those without sufficient intake of fruits and vegetables had PMS versus $13.9 \%$ who had not. About $92 \%$ of students with excess coffee intake had PMS compared to $7.7 \%$ who had not, and this difference was statistically significant $(P=0.005)$. Excessive drinking of tea had no significant influence on the PMS in this study (Table 5).

As shown in Table 6, bivariate logistic regression analysis was performed to further investigate chains of associations by taking presence of PMS as a dependent variable and their risk factors as covariates. ORs along with levels of significance of regression models were shown. A significant association was found between PMS and physical activity (OR: 0.42; 95\% CI: 0.3-0.55), vegetables and fruits (OR: 4.7; 95\% CI: 1.9-11.3), sweet food (OR: 3.02; 95\% CI: 1.8-5.1), fast food (OR: 0.41; 95\% CI: 0.17-0.97), and excess coffee intake (OR: 3.8; 95\% CI: $1.4-10.1)$.

\section{Discussion}

PMS is among the commonest gynecologic complaints in young women present to doctors [11]. The lack of data and the private nature of menstruation perpetuate the belief that menstrual complaints do not warrant the attention of the public health community [12].

The findings of the present study showed a high prevalence of PMS; it was found to be as high as $80.2 \%$. Similar findings (89\%) were reported by Bakr and Ez-Elarab (2010) in a study conducted among medical students of Ain Shams University, Egypt [13].

In this study, a significant relation between BMI and the occurrence of PMS was detected. This was in coherence with a prospective study that found a strong positive relationship between BMI and the development of PMS. Women who were obese at baseline had significantly higher risks of developing PMS over 10 years of followup compared with lean women. BMI was also positively associated with 
TABLE 3: Relation between PMS and BMI and presence of central obesity $(N=253)$.

\begin{tabular}{|c|c|c|c|c|c|c|c|}
\hline & \multicolumn{4}{|c|}{ PMS } & \multicolumn{2}{|c|}{ Total } & \multirow{3}{*}{$\begin{array}{c}\text { Fissure exact } \\
P \text { value }\end{array}$} \\
\hline & \multicolumn{2}{|c|}{ Absent $(n=50)$} & \multicolumn{2}{|c|}{ Present $(n=203)$} & \multirow[b]{2}{*}{$N$} & \multirow[b]{2}{*}{$\%$} & \\
\hline & $N$ & $\%$ & $N$ & $\%$ & & & \\
\hline \multicolumn{8}{|l|}{ BMI } \\
\hline Underweight & 0 & 0 & 4 & 100 & 4 & 100 & 14 \\
\hline Normal & 44 & 26.5 & 122 & 73.5 & 166 & 100 & $0.003^{*}$ \\
\hline Overweight & 4 & 6.6 & 57 & 93.4 & 61 & 100 & \\
\hline Obese & 2 & 9.1 & 20 & 90.9 & 22 & 100 & \\
\hline \multicolumn{8}{|l|}{ Central obesity } \\
\hline Absent & 49 & 20.5 & 190 & 79.5 & 293 & 100 & 1.5 \\
\hline Present & 1 & 7.1 & 13 & 92.9 & 14 & 100 & 0.2 \\
\hline
\end{tabular}

${ }^{*}$ Statistically significant.

TABLE 4: Relation between PMS and family history, exposure to passive smoking, and physical activity $(N=253)$.

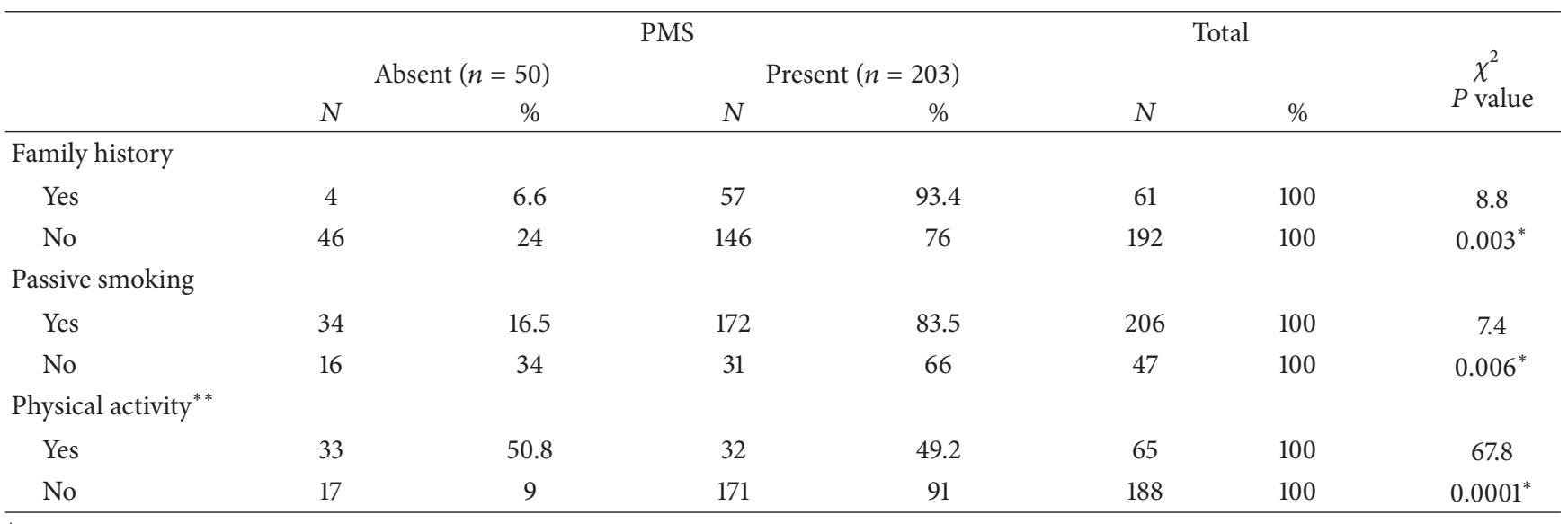

${ }^{*}$ Statistically significant.

** $20 \mathrm{~min} /$ day thrice weekly.

TABle 5: Association between PMS and dietary pattern among El-Minia students $(N=253)$.

\begin{tabular}{|c|c|c|c|c|c|c|c|}
\hline \multirow{3}{*}{ Dietary pattern } & \multicolumn{4}{|c|}{ PMS } & \multicolumn{2}{|c|}{ Total } & \multirow{3}{*}{$\begin{array}{c}\chi^{2} \\
P \text { value }\end{array}$} \\
\hline & \multicolumn{2}{|c|}{ Absent $(n=50)$} & \multicolumn{2}{|c|}{ Present $(n=203)$} & \multirow[b]{2}{*}{$N$} & \multirow[b]{2}{*}{$\%$} & \\
\hline & $N$ & $\%$ & $N$ & $\%$ & & & \\
\hline \multicolumn{8}{|l|}{ Sweet food } \\
\hline $0-2 /$ day & 34 & 29.8 & 80 & 70.2 & 114 & 100 & 13.2 \\
\hline$>3 /$ day & 16 & 11.5 & 123 & 88.5 & 139 & 100 & $0.0001^{*}$ \\
\hline Fast food mainly & 22 & 14.2 & 133 & 85.8 & 155 & 100 & 7.8 \\
\hline Homemade food mainly & 28 & 28.6 & 70 & 71.4 & 98 & 100 & $0.005^{*}$ \\
\hline \multicolumn{8}{|l|}{ Vegetables and fruits } \\
\hline $0-1 /$ day & 33 & 25.2 & 98 & 74.8 & 131 & 100 & 5 \\
\hline$>2 /$ day & 17 & 13.9 & 105 & 86.1 & 122 & 100 & $0.02^{*}$ \\
\hline \multicolumn{8}{|l|}{ Coffee } \\
\hline 1-6/week & 49 & 20.4 & 191 & 79.6 & 240 & 100 & 10.4 \\
\hline >7week & 1 & 7.7 & 12 & 92.3 & 13 & 100 & $0.005^{*}$ \\
\hline \multicolumn{8}{|l|}{ Tea } \\
\hline 1-6/week & 31 & 21.2 & 115 & 78.8 & 146 & 100 & 2.7 \\
\hline$>7 /$ week & 19 & 17.8 & 88 & 82.2 & 107 & 100 & 0.3 \\
\hline
\end{tabular}

${ }^{*}$ Statistically significant. 
TABLE 6: Logistic regression analysis of factors independently associated with PMS among the studied females $(N=253)$.

\begin{tabular}{lccc}
\hline Risk factors & OR & $95 \%$ CI for OR & $P$ \\
\hline Physical activity & 0.42 & $0.3-0.55$ & $0.0001^{*}$ \\
Vegetables and fruits & 4.7 & $1.9-11.3$ & $0.001^{*}$ \\
Sweet food & 3.02 & $1.8-5.1$ & $0.0001^{*}$ \\
Fast food & 0.41 & $0.17-0.97$ & $0.04^{*}$ \\
Excess coffee intake & 3.8 & $1.4-10.1$ & $0.008^{*}$ \\
Exposure to passive smoking & 0.48 & $0.18-1.3$ & 0.14 \\
BMI & 0.94 & $0.84-1.1$ & 0.25 \\
Family history & 0.49 & $0.16-1.5$ & 0.2 \\
\hline
\end{tabular}

N.B. dependant variable is presence of PMS.

$R^{2}=0.52$.

${ }^{*}$ Statistically significant.

OR: odds ratio; CI: confidence interval.

risk of specific physical and emotional symptoms, including swelling of the extremities, backache, abdominal cramping, diarrhea/constipation, mood swings, and food cravings [14].

Our findings of a significant association between premenstrual symptoms and a maternal history of PMS were similar to those of Wilson et al. (1991) who observed that PMS mother/daughter dyads experienced significantly more and severe luteal phase symptoms compared to non-PMS mother/daughter dyads. Shared biological and/or psychological factors, which may influence expectations and selfperceptions, may explain mother-daughter dyads $[15,16]$.

This study showed that a large proportion of students who were sedentary (91\%) had PMS compared to those women (49.2\%) who were physically active $(P<0.0001)$. This was opposite to Deuster et al. (1999) who found that women with PMS were 2.9 times more likely to be physically active than women without PMS [17]. Johnson et al. (1995) have reported that the amount of aerobic exercise was significantly associated with lower water retention, autonomic reactions, and appetite [18]. Aerobic exercise seems to have more beneficial effect on premenstrual symptoms than anaerobic exercise, especially with respect to premenstrual depression [19].

Our findings of a significant association between PMS symptoms and intake of sweet-tasting foods were in agreement with the observations of Rasheed and Saad (2003) who found this association. This points to the need for educating PMS sufferers on curtailing these dietary items [20].

Our study also showed a significant, positive, and independent effect on PMS by coffee drink. This was similar to the results of Rasheed and Saad (2003) who found a significant positive effect on premenstrual symptom severity by total intake of caffeinated beverages in general and caffeinated coffee and cocoa-chocolate drinks in particular. Phillis (1989) suggested that the depressive action of adenosine on central neurons was the mechanism by which caffeine might cause PMS [21]. The observed effect of tea did not reach significant levels possibly due to a lower dose effect of caffeine per cup for these beverages compared to coffee. As per standard values, one cup (5-6 oz) of caffeinated coffee usually has $60-85 \mathrm{mg}$ of caffeine while that for tea and cola drinks is reported to be 20-30 mg and $18 \mathrm{mg}$ per cup, respectively [22].

The logistic regression analysis showed that physical inactivity, exposure to passive smoking, frequent intake of sweet-tasting food items, fast food, decreased vegetables and fruits, and caffeinated beverages explained only $52 \%$ of the variation in the PMS. Various studies have suggested other putative causes: hormonal imbalance and psycho-social disorders (Ramcharan et al. (1992)), none of which were investigated by us [23]. No single theory has been established to explain the entire diversity of PMS symptomatology. More explanatory research is required to unravel the etiological factors of PMS and its pathophysiological mechanism.

\section{Limitations of the Study}

(i) Female with PMS may be more interested in participating in this study more than females without PMS and this could lead to selection bias.

(ii) This cross-sectional study allowed studying associations but not causality.

\section{Conclusion and Recommendations}

Based on the findings of the present study, it was concluded that: PMS was highly prevalent among the college students. PMS was significantly associated with increase of BMI, sedentary life style, exposure to passive smoking, positive family history of PMS, excessive coffee drinking, and frequent consumption of fast food.

It was recommended that the introduction of a reproductive health component into school and college health education program could help in providing correct and current information, education, and support to students regarding reproduction in general and menstrual problems in particular.

It is imperative to encourage the female adolescents to adopt a healthy life style, which includes appropriate healthy nutrition, increasing the vitamin intake in their food by increasing the vegetables and fruits. Cutting of the added salt in their food, as well as eliminating caffeine containing beverages, particularly coffee, from their diet would be essential for those have troublesome menses with PMS.

Additional studies may be needed using a wider geographic scope and a larger sample.

It is essential to make treatment available for girls. Many girls may feel shy and may be reluctant to report PMS and, consequently, do not seek medical advice which may in turn negatively impact both academic life and educational achievements and quality of life and activities of daily living. It is one of the roles of health care providers in the respective institutions to ask about and screen for PMS offer treatment if necessary.

\section{Conflict of Interests}

No conflict of interests was declared. 


\section{Acknowledgment}

The authors are very much grateful to all participants of the study for their kind cooperation.

\section{References}

[1] K. J. Ryan, R. S. Berkowitz, R. L. Barbieri, and A. E. Dunaif, Kistner's Gynecology and Women's Health Nursing, Mosby, 7th edition, 1999.

[2] M. E. Mc Pherson and L. Korfine, "Menstruation across time: menarche, menstrual attitudes, experiences, and behaviors," Women's Health Issues, vol. 14, no. 6, pp. 193-200, 2004.

[3] A. H. El-Gilany, K. Badawi, and S. El-Fedawy, "Epidemiology of dysmenorrhoea among adolescent students in Mansoura, Egypt," Eastern Mediterranean Health Journal, vol. 11, no. 1-2, pp. 155-163, 2005.

[4] American College of Obstetrics and Gynecology: ACOG practice bulletin: premenstrual syndrome, ACOG, Washington, DC, USA, April 2000.

[5] K. A. Yonkers, P. M. S. O’Brien, and E. Eriksson, "Premenstrual syndrome," The Lancet, vol. 371, no. 9619, pp. 1200-1210, 2008.

[6] A. O. Adewuya, O. M. Loto, and T. A. Adewumi, "Pattern and correlates of premenstrual symptomatology amongst Nigerian University students," Journal of Psychosomatic Obstetrics and Gynecology, vol. 30, no. 2, pp. 127-132, 2009.

[7] P. M. S. O'Brien, “The premenstrual syndrome. A review," The Journal of Reproductive Medicine, vol. 30, pp. 113-126, 1985.

[8] K. M. Alami, S. M. Tahiri, D. Moussaoui, and N. Kadri, "Assessment of premenstrual dysphoric disorder symptoms: population of women in Casablanca," Encephale, vol. 28, no. 6, part 1, pp. 525-530, 2002.

[9] G. M. Lentz, "1ry, 2nd dysmenorrhea, PMS and premenstrual dysphoric disorder: etiology, diagnosis, management," in Comprehensive Gynecology, G. M. Lentz, R. A. Lobo, D. M. Gershenson, and V. L. Katz, Eds., chapter 36, Mosby, Elsevier, Philadelphia, Pa, USA, 6th edition, 2012.

[10] E. R. Bertone-Johnson, S. E. Hankinson, S. R. Johnson, and J. E. Manson, "A simple method of assessing premenstrual syndrome in large prospective studies," The Journal of Reproductive Medicine, vol. 52, no. 9, pp. 779-786, 2007.

[11] C. Banikarim, M. R. Chacko, and S. H. Kelder, "Prevalence and impact of dysmenorrhea on Hispanic female adolescents," Archives of Pediatrics \& Adolescent Medicine, vol. 154, no. 12, pp. 1226-1229, 2000.

[12] G. Walraven, G. Ekpo, R. Coleman, C. Scherf, L. Morison, and S. D. Harlow, "Menstrual disorders in rural Gambia," Studies in Family Planning, vol. 33, no. 3, pp. 261-268, 2002.

[13] I. Bakr and H. S. Ez-Elarab, "Prevalence of premenstrual syndrome and the effect of its severity on the quality of life among medical students," The Egyptian Journal of Community Medicine, vol. 28, no. 2, 2010.

[14] E. R. Bertone-Johnson, S. E. Hankinson, W. C. Willett et al., "Adiposity and the development of premenstrual syndrome," Journal of Women's Health, vol. 19, no. 11, pp. 1955-1962, 2010.

[15] C. A. Wilson, C. W. Turner, and W. R. Keye Jr., "Firstborn adolescent daughters and mothers with and without premenstrual syndrome: a comparison," Journal of Adolescent Health, vol. 12, no. 2, pp. 130-137, 1991.

[16] E. W. Freeman, S. J. Sondheimer, and K. Rickels, "Effects of medical history factors on symptom severity in women meeting criteria for premenstrual syndrome," Obstetrics and Gynecology, vol. 72, no. 2, pp. 236-239, 1988.

[17] P. A. Deuster, T. Adera, and J. South-Paul, "Biological, social, and behavioral factors associated with premenstrual syndrome," Archives of Family Medicine, vol. 8, no. 2, pp. 122-128, 1999.

[18] W. G. Johnson, R. E. Carr-Nangle, and K. C. Bergeron, "Macronutrient intake, eating habits, and exercise as moderators of menstrual distress in healthy women," Psychosomatic Medicine, vol. 57, no. 4, pp. 324-330, 1995.

[19] J. F. Steege and J. A. Blumenthal, "The effect of aerobic exercise on premenstrual symptoms in middle-aged women: a preliminary study," Journal of Psychosomatic Research, vol. 37, no. 2, pp. 127-133, 1993.

[20] P. Rasheed and L. A. Saad, "Prevalence and predictors of premenstrual syndrome among college-aged women in Saudi Arabia," Annals of Saudi Medicine, vol. 23, no. 6, pp. 381-387, 2003.

[21] J. W. Phillis, "Caffeine and premenstrual syndrome," American Journal of Public Health, vol. 79, no. 12, p. 1680, 1989.

[22] J. J. Barone and H. R. Roberts, "Caffeine consumption," Food and Chemical Toxicology, vol. 34, no. 1, pp. 119-129, 1996.

[23] S. Ramcharan, E. J. Love, G. H. Fick, and A. Goldfien, "The epidemiology of premenstrual symptoms in a population-based sample of 2650 urban women: attributable risk and risk factors," Journal of Clinical Epidemiology, vol. 45, no. 4, pp. 377-392, 1992. 


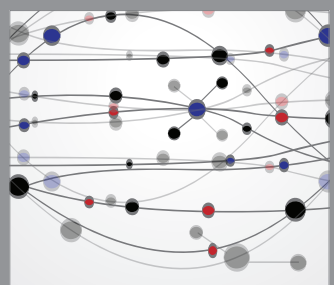

The Scientific World Journal
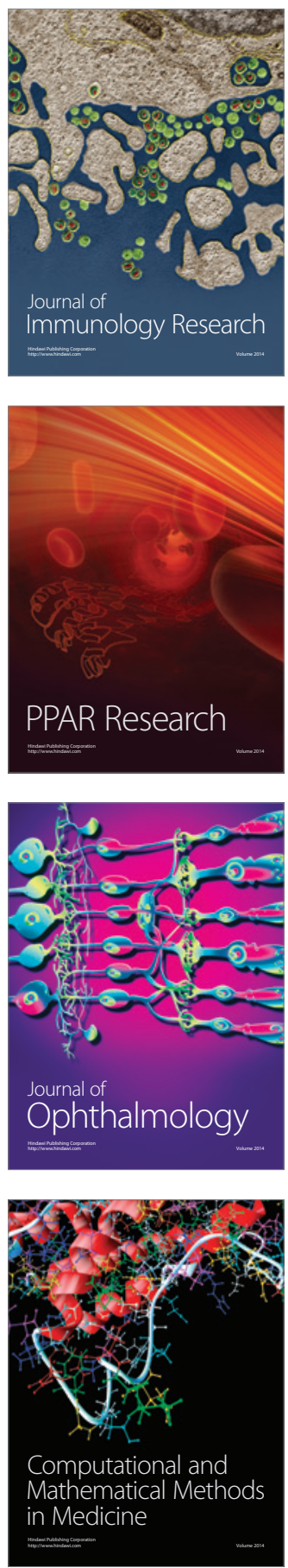

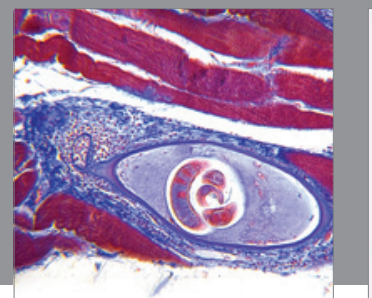

Gastroenterology

Research and Practice
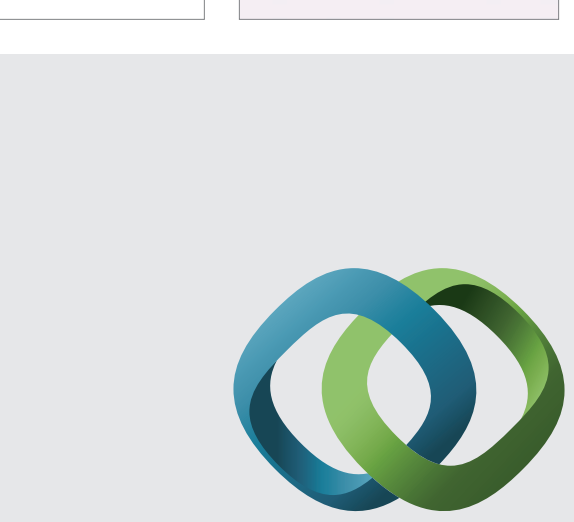

\section{Hindawi}

Submit your manuscripts at

http://www.hindawi.com
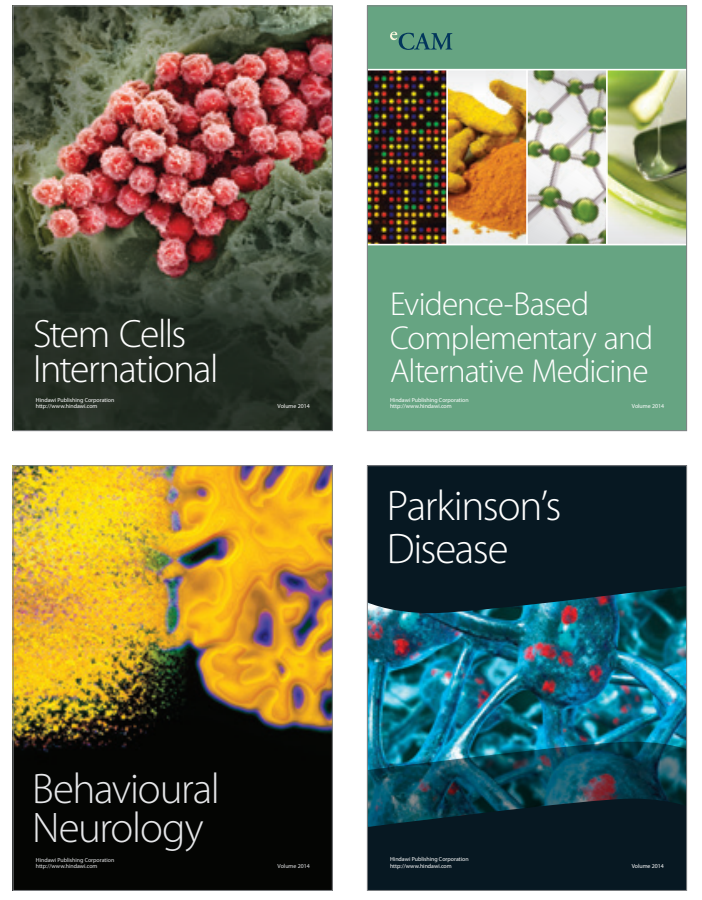
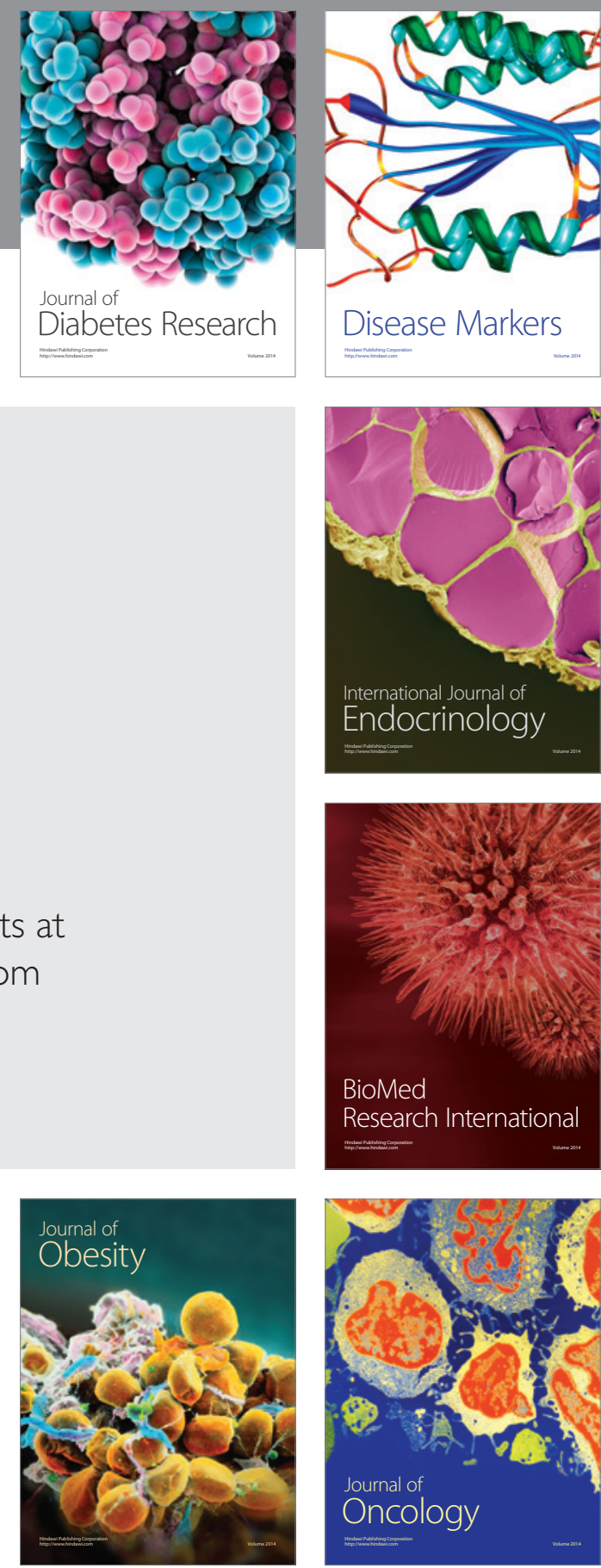

Disease Markers
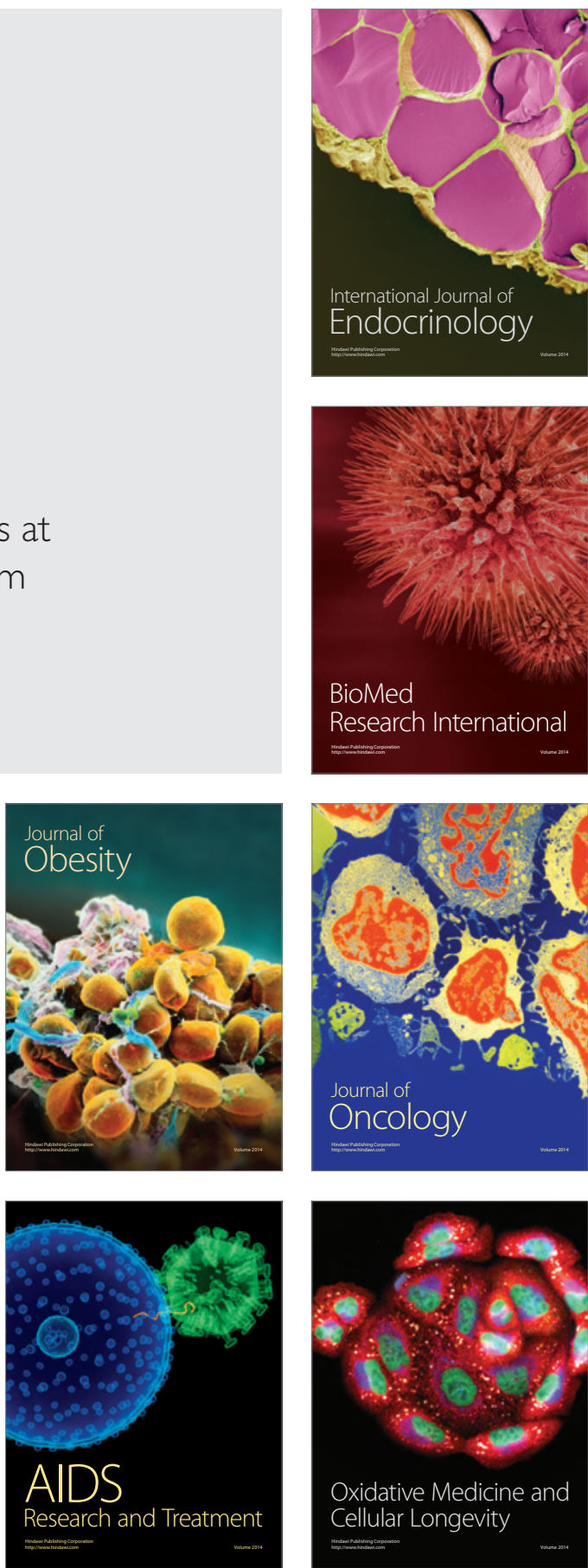